\title{
Incidence of the Diagnosis of Anxiety Disorders in the Russian Federation: Results of a Web-Based Survey of Psychiatrists
}

\author{
Sergey N. Mosolov (D) - Ivan A. Martynikhin • Timur S. Syunyakov • \\ Timofey L. Galankin • Nikolay G. Neznanov
}

Received: July 22, 2021 / Accepted: August 18, 2021 / Published online: August 30, 2021

(C) The Author(s) 2021

\begin{abstract}
Introduction: According to the official Russian source, in 2017 only $0.27 \%$ of the population of Russia was diagnosed with International Classification of Diseases, tenth revision (ICD-10) F4 category disorders (neurotic, stress-related and somatoform disorders), despite these disorders being among the most prevalent mental disorders worldwide. Here we report the results of a largescale survey among Russian psychiatrists with the primary objective to assess the proportion of
\end{abstract}

S. N. Mosolov (ه)

Moscow Research Institute of Psychiatry, 3,

Poteshnaya ul., 107076 Moscow, Russia

e-mail: profmosolov@mail.ru

S. N. Mosolov

Russian Medical Academy of Continuous

Professional Education, Moscow, Russia

I. A. Martynikhin - T. L. Galankin · N. G. Neznanov The First Pavlov State Medical University of St. Petersburg, St. Petersburg, Russia

T. S. Syunyakov

Research Zakusov Institute of Pharmacology,

Moscow, Russia

T. S. Syunyakov

Mental-Health Clinic No. 1 Named After N.A.

Alexeev Education Center, Department of Health of Moscow, Moscow, Russia

N. G. Neznanov

St. Petersburg V.M. Bekhterev Psychoneurological

Research Institute, St. Petersburg, Russia psychiatrists who use the diagnoses of interest (mixed anxiety and depression disorder [MADD], adjustment disorder [AdD], panic disorder [PD], agoraphobia, generalized anxiety disorder [GAD], social phobia, simple phobia, acute stress disorder and posttraumatic stress disorder) and compare results with those of a recent World Psychiatric Association (WPA) and World Health Organization (WHO) survey. We also compared the incidence of these diagnoses between state and nonstate psychiatric services in Russia.

Methods: Mean proportions and distribution of proportions of participants who made diagnoses of interest at different rates were calculated and compared with the results of the recent WPA and WHO survey. Risk ratios (RR) of the incidence of these diagnoses made at a frequency of at least once a week were calculated to compare state and non-state psychiatric services. The 95\% confidence intervals of the RRs were calculated using the Koopman asymptotic score method.

Results: Responses of 960 Russian psychiatrists were included in the analysis. Of these 95, 89 and $87 \%$ reported making diagnoses of MADD, AdD and $\mathrm{PD}$, respectively, during the preceding 12 months, a far larger proportion compared to other disorders of interest. In general, a significantly smaller proportion of participants in our survey made diagnoses of anxiety disorders compared to respondents in the international WPA-WHO survey. Based on RRs, diagnoses of MADD, AdD, PD, GAD and acute stress disorder were less frequently made in the state-operated psychiatric service. 
Conclusion: Our survey revealed a serious underdiagnosis of anxiety disorders in Russia that may be associated with complex factors that include, but are not limited to the current stigma associated with the state-operated psychiatric service, which is still the exclusive source of official statistical data in Russia.

Keywords: Anxiety disorders; Online survey; Russian Federation; Diagnosis usage

\section{Key Summary Points}

\section{Why carry out this study?}

According to the official Russian agency, in 2017 only $0.27 \%$ of the population of Russia was diagnosed with International Classification of Diseases, tenth revision (ICD-10) F4 category disorders (neurotic, stress-related and somatoform disorders), despite these disorders being among the most prevalent mental disorders worldwide.

In a large-scale survey among Russian psychiatrists we assessed the proportion of psychiatrists who made diagnoses of different anxiety disorders in real practice and compared the results with data from the international survey carried out by the orld Psychiatric Association and World Health Organization (WPA-WHO).

\section{What was learned from this study?}

A significantly smaller proportion of respondents in our survey made diagnoses of anxiety disorders compared to those in the international WPA-WHO survey.

The most frequent diagnoses during the preceding 12 months were mixed anxiety and depression disorder, adjustment disorder and panic disorder.

The results reveal an underdiagnosis of anxiety disorders in Russia that may be associated with complex factors, including the current professional education system and the stigma associated to the state-operated psychiatric service.

\section{INTRODUCTION}

Recent publications have reported on the many challenges and barriers found in the mental health system in Russia in terms of organization, stigma, psychiatric training and socioeconomical changes [1-8]. Although the mental healthcare system in Russia is undergoing a transition from an institutional model to deinstitutionalized model, official statistics on the incidence and prevalence of mental disorders remain institution based and, according to an issue of the statistical bulletin of the Ministry of Health of Russian Federation, only $2.7 \%$ of the Russian population utilized psychiatric system resources in 2018 [9]. The prevalence of anxiety disorders (ADs) in Russia seems to be severely underestimated. In 2013, the Ministry of Health of the Russian Federation reported that only $0.27 \%$ of the population was diagnosed in that year with neurotic, stress-related and somatoform disorders [10].

A meta-analysis of epidemiological studies conducted in the last 30 years around the world estimated that the average 1-year and lifetime prevalence of $\mathrm{AD}$ is 6.2 and $12.9 \%$, respectively [11]. In Europe, the 12-month prevalence of ADs was found to exceed the prevalences of all other classes of mental disorders, including affective disorders and addictions [12]. The reasons for this large difference in reported prevalence of $\mathrm{AD}$ between Russia and other countries are unknown but may be associated with both patient and healthcare factors. First, people with $\mathrm{AD}$ may be not be aware of having a mental disorder; alternatively, they may wish to avoid state-operated mental health services due to associated historical stigma and turn instead to non-state-operated community psychiatric services (e.g. private practice, psychiatric units in general hospitals and primary care units, among others). Second, psychiatrists in Russia may simply not detect $\mathrm{AD}$ or may diagnose other comorbidities instead.

We conducted a large-scale survey among Russian psychiatrists with the primary objective to assess the proportion of psychiatrists who used specific diagnostic codes in the International Classification of Diseases, tenth revision (ICD-10) F4 category (neurotic, stress-related 
and somatoform disorders). In this article we elaborate on the main results of the survey, which were previously published in a Russian scientific journal, as well as on new data originating from an additional analysis we performed to compare the incidence of diagnoses of interest in state- and non-state-operated psychiatric services in Russia [13]. In 2011, the results of the international survey conducted by the World Psychiatric Association (WPA) and World Health Organization (WHO) [14], involving 4887 responding psychiatrists from 44 countries, were published. We compared the frequency of diagnoses reported in the WPA/ WHO survey with our findings and with the official data reported for Russia. Our secondary objective was a comparison of the use of diagnoses between participants who reported they work in the state- and non-state-operated psychiatric services, since the official Russian statistics are based on epidemiological data captured from state institutions. We also analyzed specialists' attitudes toward the use of these diagnoses and adherence to current treatment guidelines.

\section{METHODS}

The RSP conducted an online survey of psychiatrists. Following approval of the study and the design of the survey by the Local Ethics Committee of Moscow Research Institute of Psychiatry, the survey was placed on the SoSci Survey online survey platform (https://www. soscisurvey.de/). The following specific ICD-10 diagnoses of interest were covered by the questionnaire: agoraphobia (F40.0), social phobia (F40.1), specific phobias (F40.2), panic disorder (PD) (F41.0), generalized anxiety disorder (GAD) (F41.1), mixed anxiety and depressive disorder (MADD) (F41.2), acute stress reaction (ASR) (F43.0), posttraumatic stress disorder (PTSD) (F43.1) and adjustment disorder (AdD) (F43.2).

The questionnaire included 21 main questions. The GAD diagnosis was chosen to probe the specialist's attitude toward the diagnosis of $\mathrm{GAD}$, diagnostic habits and adherence to contemporary treatment guidelines, as GAD is the most recent diagnostic category of $\mathrm{AD}$ adopted in Russia [15] and tends to be a comorbid diagnosis [16, 17]. Depending on whether a respondent made a diagnosis of GAD in the past year or not, the respondent was asked additional questions that focused on the management of patients with GAD (9 questions) or the reasons why the diagnosis was not made (2 questions). Many questions consisted of several items. Therefore, each participant answered between 62 and 96 questions. Various types of questions were included (single-item, multiplechoice and open questions; questions using a rating, score or visual analog scale). The survey form included five sections, each of which focused on different areas: (1) respondent's professional training and clinical practice conditions; (2) number of patient visits involving $\mathrm{AD}$; (3) attitude towards the diagnosis of AD; (4) specific questions on either GAD diagnosis and management or reasons for not diagnosing $\mathrm{GAD}$; (5) treatment practices of $\mathrm{AD}$.

\section{Participants}

The survey was conducted from November 2016 to February 2017. Survey data were collected in two waves. During the first wave, the questionnaire was sent to psychiatrists registered on the RSP website (https://psychiatr.ru/). At the time of the survey, the database of the RPS website included the email addresses of 3091 psychiatrists. Before the start of the second wave of this survey, an open-access link to the questionnaire and call for the psychiatrists to participate in the survey was posted on the RSP website. Only the responses of those participants who psychiatrists, have a clinical practice in the Russian Federation and use psychiatric diagnoses in their clinical practice were included in the analysis. Individuals were not allowed to participate in the survey twice.

\section{Ethics Considerations}

This study was not experimental research and did not involve any patients. All data were received from an anonymous online survey of psychiatrists who voluntarily responded to the questions in the survey. The study did not 


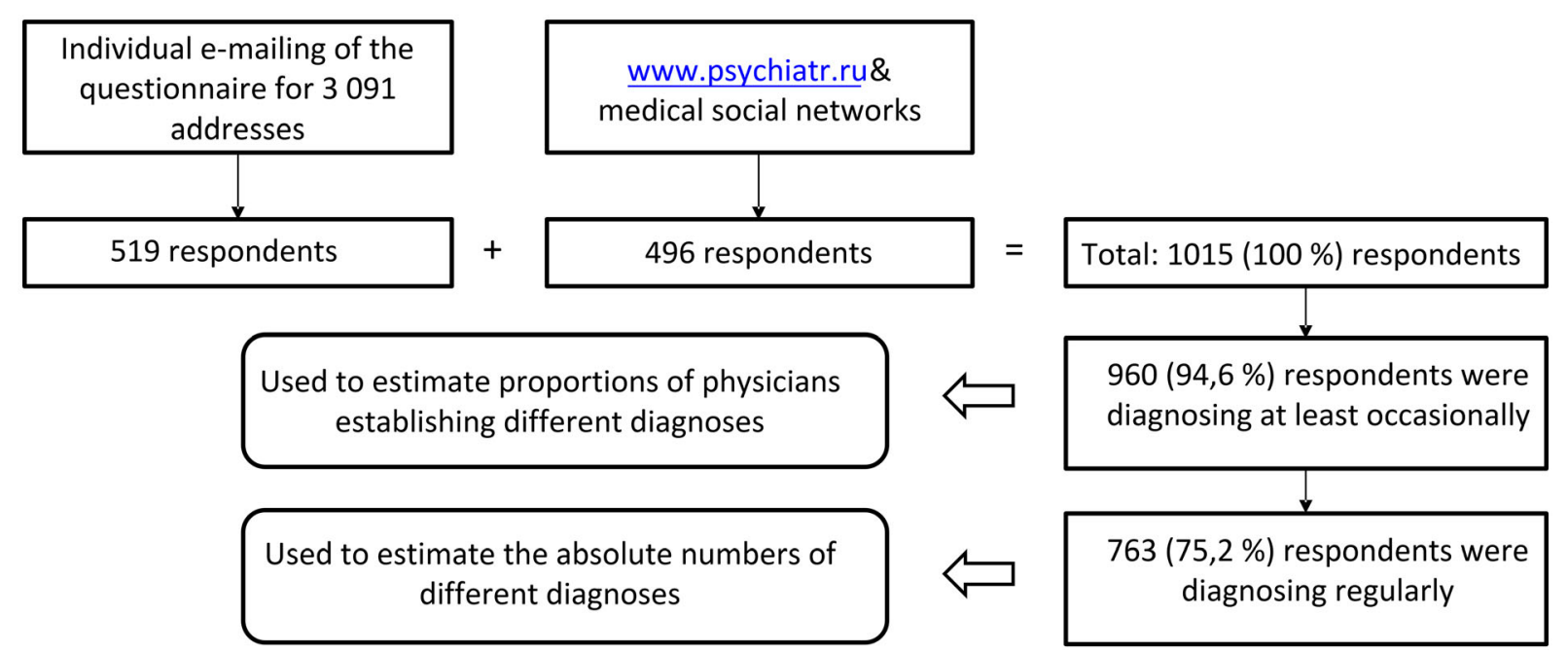

Fig. 1 Flow chart of inclusion of participants in study

involve the collection of any personal data. The study and the content of the survey were approved by the Local Ethical Committee of Moscow Research Institute of Psychiatry (19 September 2016; protocol no. 34a), and written participation consent was waived. The study followed the Good Epidemiology Practice guidelines and the principles of the Declaration of Helsinki.

\section{Statistical Methods}

Statistical analysis was conducted using R software version 3.5.1 (2018; R Foundation for Statistical Computing, Vienna, Austria).

Participants responded to questions on their use of diagnoses of anxiety, phobic, stress-related or mixed anxiety-depressive disorders by choosing one of the following categories: "not once," "1-2 diagnoses per year," "1-2 diagnoses per month," "1-2 diagnoses per week" or " $1-2$ diagnoses per day." The proportions of these categories were analyzed among the respondents who were engaged in the diagnosis of mental disorders at least occasionally (study population $N=960,95 \%$ of total respondents). The mean numbers of participants who used the diagnoses of interest at least 1-2 times a week were compared with the results of the WPA-WHO survey [14]. The source data of the
WPA-WHO survey for RSP were received from the authors of that survey after our survey data had been collected. The 95\% confidence intervals (CIs) were estimated on the basis of binomial distribution.

Respondents' ranking of eight classes of drugs was analyzed for all respondents who answered the corresponding question $(n=765$, $75.4 \%$ ). If a respondent ranked only some of the proposed classes of drugs, the remaining classes were given the next rank (e.g., if only 4 classes of drugs were ranked, all unranked classes were ranked as 5). 95\% CIs were calculated via bootstrapping respondents' identifiers (1000 random samples with replacement).

Relative risks (RR) of the use of these diagnoses at least once a week were calculated to compare state and non-state psychiatric services. The $95 \%$ CIs of the RR were calculated using the Koopman asymptotic score method.

\section{RESULTS}

The first wave consisted of sending the questionnaire directly to all psychiatrists registered on the RSP website. Ultimately, 519 psychiatrists responded to the questionnaire and participated in the survey, which is a response rate of $17 \%$. This response rate is acceptable for an 
Table 1 General characteristics of responding psychiatrists who currently had a regular clinical practice for at least 1 year prior to participating in the survey and had diagnosed mental disorders

\begin{tabular}{|c|c|c|}
\hline $\begin{array}{l}\text { General characteristics of responding } \\
\text { psychiatrists }\end{array}$ & $\begin{array}{l}n(N=960 \text { eligibile participating } \\
\text { psychiatrists })\end{array}$ & $\begin{array}{l}\text { Mean }(95 \% \mathrm{CI}) \text { experience, } \\
\text { years }\end{array}$ \\
\hline \multicolumn{3}{|l|}{ Clinical practice } \\
\hline Everyday practice & 737 & $17.4(16.6,18.1)$ \\
\hline Seldom & 178 & $14.1(12.5,15.6)$ \\
\hline No in past year & 14 & $11.4(5.8,17.1)$ \\
\hline No & 31 & $14.9(10.4,19.5)$ \\
\hline \multicolumn{3}{|l|}{ Gender } \\
\hline Men & 389 & $18.3(17.2,19.5)$ \\
\hline Women & 571 & $15.4(14.6,16.2)$ \\
\hline \multicolumn{3}{|l|}{ Working settings } \\
\hline \multicolumn{3}{|l|}{ Non-state } \\
\hline \multicolumn{3}{|l|}{ Gender } \\
\hline Men & 222 & $19.3(17.7,21.0)$ \\
\hline Women & 250 & $17.1(15.8,18.4)$ \\
\hline \multicolumn{3}{|l|}{ Clinical practice } \\
\hline Everyday practice & 352 & $19.0(17.8,20.2)$ \\
\hline Seldom & 100 & $15.6(13.4,17.8)$ \\
\hline No in past year & 9 & $13.7(4.8,22.5)$ \\
\hline No & 11 & $16.4(7.2,25.6)$ \\
\hline Subtotal & 472 & $18.1(17.1,19.2)$ \\
\hline \multicolumn{3}{|l|}{ State } \\
\hline \multicolumn{3}{|l|}{ Gender } \\
\hline Men & 167 & $17.0(15.3,18.8)$ \\
\hline Women & 321 & $14.1(13.0,15.2)$ \\
\hline \multicolumn{3}{|l|}{ Clinical practice } \\
\hline Everyday practice & 385 & $15.9(14.8,16.9)$ \\
\hline Seldom & 78 & $12.0(9.9,14.2)$ \\
\hline No in past year & 5 & $7.4(3.4,11.4)$ \\
\hline No & 20 & $14.2(8.6,19.7)$ \\
\hline Subtotal & 488 & $15.1(14.2,16.0)$ \\
\hline Total & 960 & $16.6(15.9,17.3)$ \\
\hline
\end{tabular}

CI Confidence interval 
online survey in terms of ensuring the possibility to distinguish between responders and non-responders. The second wave consisted of an open-access link to the questionnaire posted on the RSP website; after excluding non-psychiatrists and psychiatrists from other countries, data from a further 496 specialists were extracted. Thus, a total of 1015 Russian psychiatrists participated in this survey. The flow chart of participant inclusion in the study is shown in Fig. 1. Of all participants, 688 respondents (68\%) answered all questions, and 327 respondents gave answers to at least a couple of key questions of the questionnaire, including the question on their use of diagnoses of ADs. The average time spent by the respondents on the survey was $23 \mathrm{~min}$.

Psychiatrists from 75 of 85 regions of the Russian Federation participated in the survey; almost a quarter of respondents were from Moscow (16\%) and Saint Petersburg (9\%). Women represented $59 \%$ of respondents. The largest proportion of respondents (44\%) noted that they work as staff healthcare professionals in an outpatient setting; 25\% noted they worked in an in-patient setting; and 15\% indicated that they are consulting psychiatrists in the area of somatic medicine (both in- and outpatient settings). About $15 \%$ of respondents represented academic and administrative staff. The average number of years of experience in psychiatry of respondents was 16.9 years [median 16.0, interquartile range (IQR) 8.0-23.5]. Overall, 194 respondents (19\%) had a scientific background, among whom $194(19 \%)$ had a PhD degree. The majority $(n=995,98 \%)$ of respondents had a regular clinical practice for at least 1 year prior to taking the survey. Overall, 960 (95\%) of the responding psychiatrists used the specified diagnoses of mental disorders, and they were considered to be the study population and their data was used for this study; 737 (77\%) stated that diagnostic interview is a part of their everyday work. The general characteristics of these 960 psychiatrists are found in Table 1.

\section{Proportion of Psychiatrists Who Used Diagnoses of Interest}

Almost all psychiatrists ( $n=949 ; 98.9 \%)$ made diagnoses of interest in the previous 12 months (Fig. 2). Of all diagnoses made during the last 12 months, the most frequent was MADD (95\% of psychiatrists), followed by AdD (89\%), PD (87\%), ASR (85\%), GAD (85\%), PTSD (75\%), specific phobias (62\%), social phobia (58\%) and agoraphobia (54\%). On a weekly basis, each specific diagnosis was used by less than half of psychiatrists, ranging from $42.5 \%$ for MADD to $4.0 \%$ for Specific phobias.

Among participants who diagnosed mental disorders on a daily basis, $14.6 \% \quad(n=140)$ reported that they had never used the diagnosis of GAD in the last 12 months. Most of these respondents $(84 \%$, with half of them working in psychiatric hospitals) did not see patients who met GAD criteria, while the remainder (16\%) reported that they did not diagnose GAD because they are not aware of its diagnostic criteria or used different diagnoses.

Despite the participants noting that $66.0 \%$ of their patients (IQR 43.0-81.0\%) had anxiety and/or nervousness symptoms, $84 \%$ of the responders never made a concurrent diagnosis, $59 \%$ found that the use of comorbid diagnoses is impractical and $17 \%$ considered that the use of these comorbid diagnoses was inappropriate.

\section{Comparison to WPA-WHO Survey Results}

The distribution pattern of the use of ICD-10 F4 category diagnoses in Russia was found to be very different from that in the WPA-WHO survey, as shown in Fig. 3. Overall, a smaller proportion of psychiatrists in Russia used diagnoses of interest compared to the results of the international WPA-WHO survey, with the exception of panic disorder (F41.0). The diagnosis of MADD (F41.2) was the most commonly used diagnosis in both surveys, with 66.7 and $42.5 \%$ of participating psychiatrists in the WPA-WHO and current RSP survey, respectively, using this diagnosis at least once a week. As expected, the greatest differences between the results of the WPA-WHO and RSP surveys were found in the 


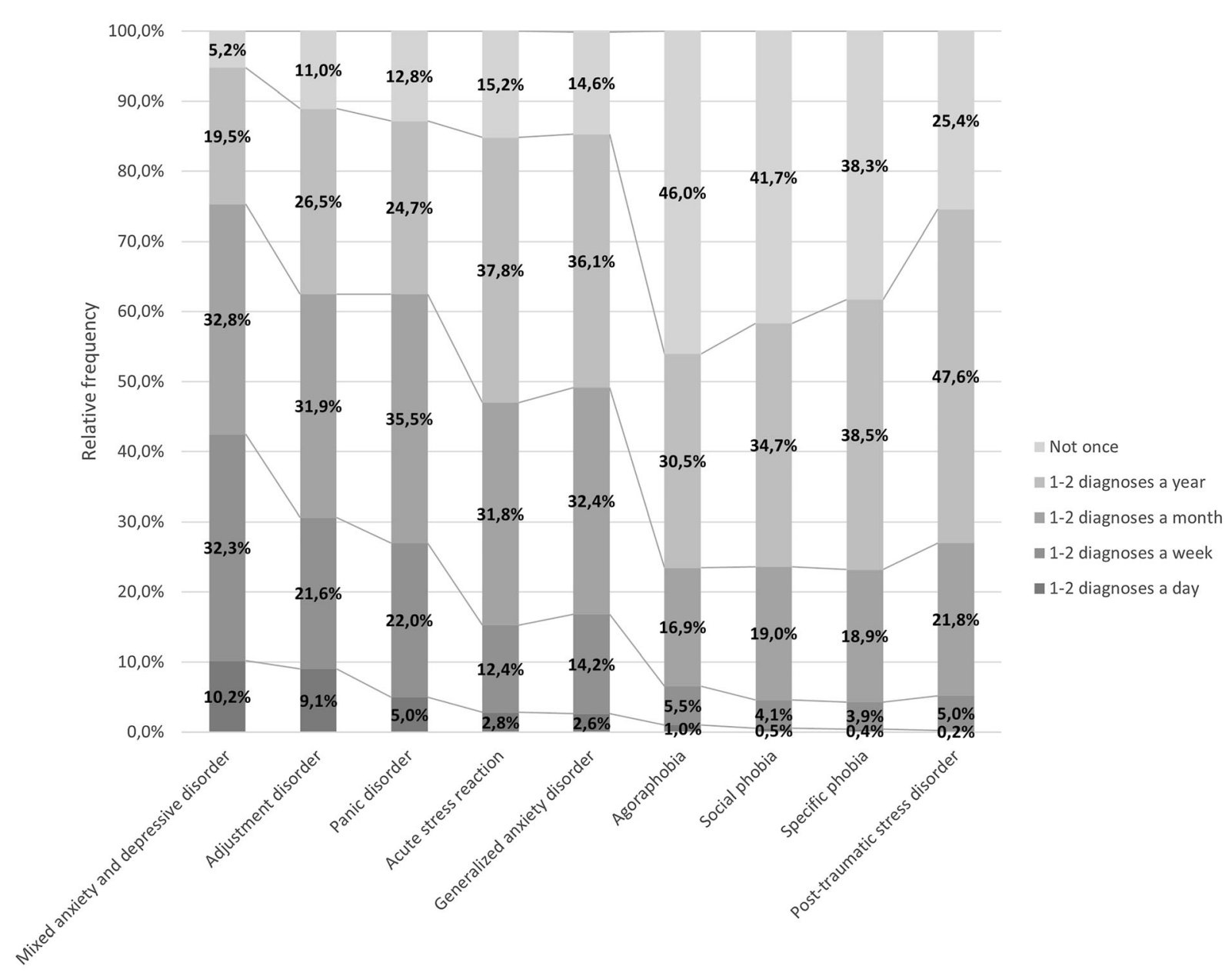

Diagnoses, ICD-10

Fig. 2 The distribution of proportions of psychiatrists who diagnosed anxiety disorders (ICD-10 F4 category codes) on a daily, weekly, monthly and yearly basis (study population, $N=960$ )

relative frequency of use of diagnoses of specific phobias (F40.2) and GAD (F41.1): 48 and 43\%, respectively. The diagnosis of AdD (F43.2) was the third most frequent diagnosis in the WPA-WHO survey and second in the RSP survey (52.9 and 30.6\%, respectively).

We also compared our findings with WPA-WHO Russian strata results. The WPA-WHO results for Russia were based on the responses of 220 psychiatrists, while the population in our study was 4.3-fold larger. The results of the WPA-WHO data for Russia from 2011 (Fig. 3) were closer to international results than our data, and the use of most frequent diagnosis of MADD remained almost unchanged.

\section{Comparison of the Use of Diagnoses of Interest in State and Non-state Settings}

Among those respondents whose answers were included in the analysis, 488 and 472 reported that they work in a state and non-state psychiatric service, respectively. The RRs of the use of the diagnoses of interest in both types of psychiatric services are shown in Fig. 4. Overall, the RRs indicate a moderate inclination toward the increased use of the five most frequently used 


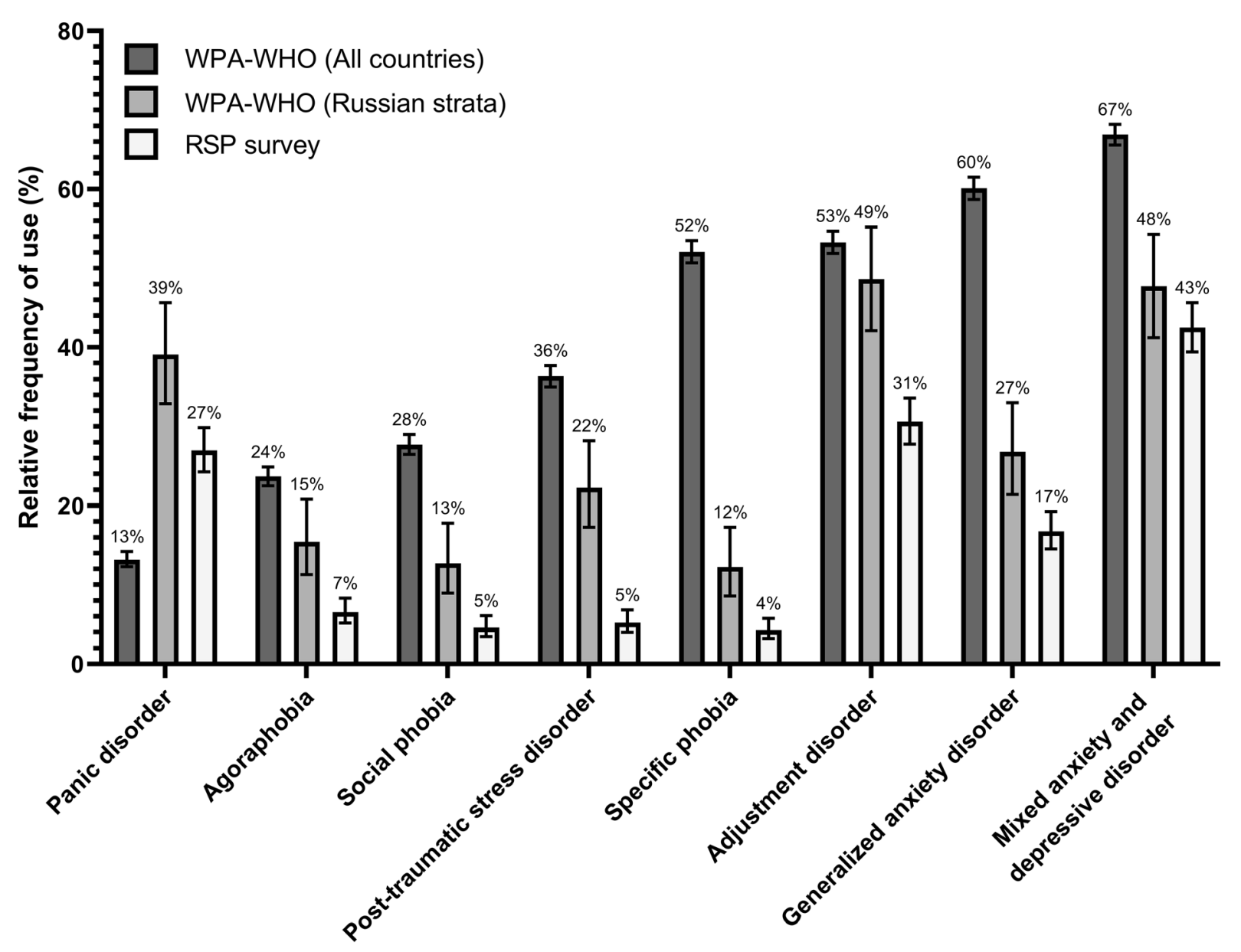

Diagnosis, ICD-10

Fig. 3 Comparison of proportions of respondents who used diagnoses of interest at least once a week in our study and in the Russian strata of the WPA-WHO survey. Results of the WPA-WHO $(N=4887)$ [4], WPA-WHO Russian strata $(N=220)$ and RSP (study population, $N=960$ ) surveys are compared. The diagnosis

diagnoses of interest in the non-state psychiatric service settings.

\section{Attitude Towards Treatment}

Respondent's drug choice for the treatment of anxiety and phobic disorders generally complied with current international clinical guidelines $[18,19]$. Figure 5 shows the proportions of psychiatrists who considered specific drugs as first-, second- or third-line treatments or as an add-on treatment for ADs. Most respondents of "acute stress reaction" was not included in the list of diagnostic categories of the WPA-WHO survey, so it was excluded from the comparison. Error bars show $95 \%$ confidence intervals

considered selective serotonin reuptake inhibitors (SSRIs) as the first line treatment; in addition, $96 \%$ of respondents chose SSRIs as essential for any treatment line. SSRIs as treatment were followed by atypical anxiolytics (i.e. hydroxyzine, buspirone), serotonin-norepinephrine reuptake inhibitors (SNRIs), pregabalin, benzodiazepines and tricyclic antidepressants.

More than $90 \%$ of participants followed up treatment response and decided whether a change in medication was necessary during the 


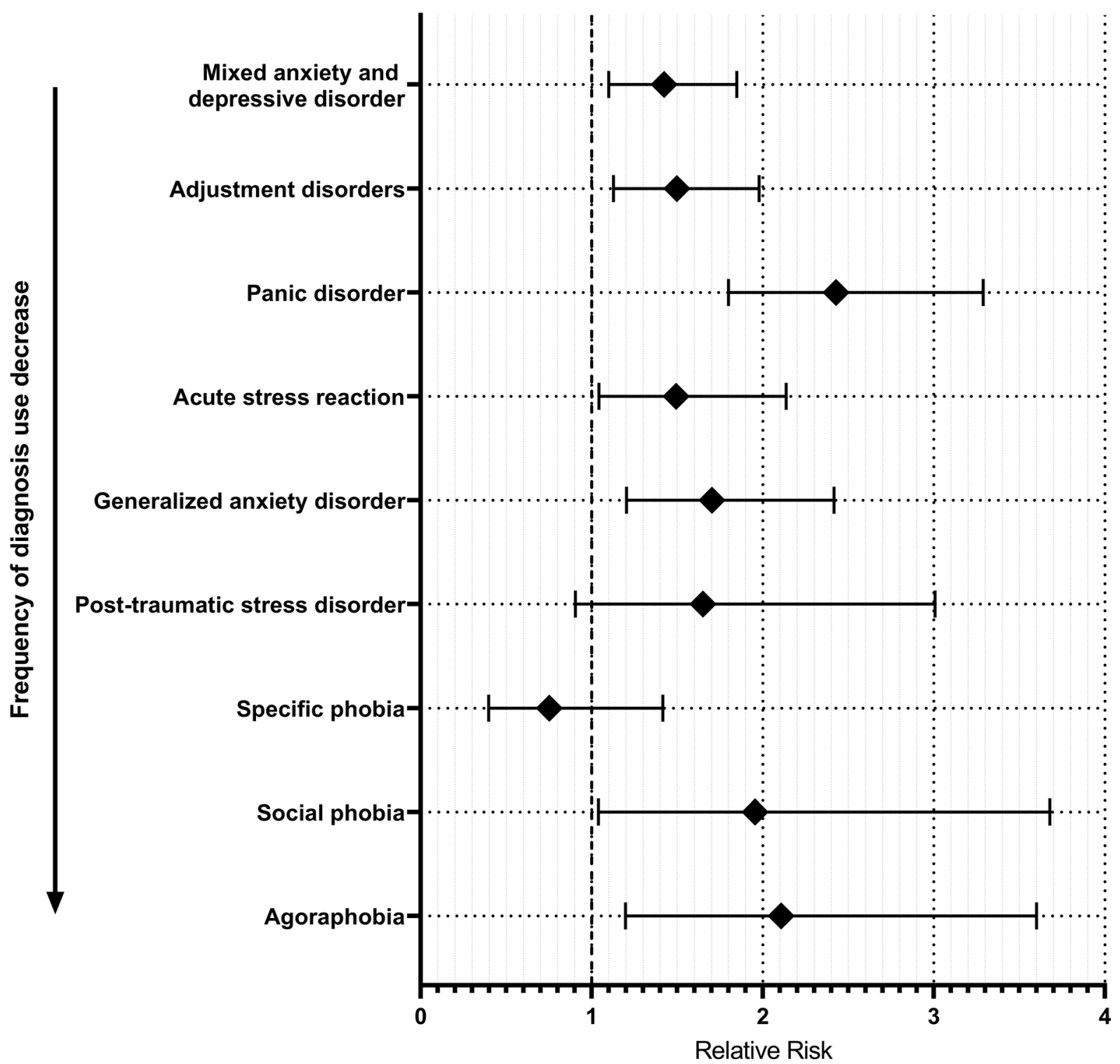

Fig. 4 Relative risk (with $95 \%$ confidence interval) of the use of the diagnoses of interest at least once a week in state $(n=488)$ and non-state $(n=472)$ psychiatric services

period from the first days after treatment initiation to $2-4$ weeks thereafter $(32,28,20$ and $8 \%$ within 1-2 weeks, 2-4 weeks, 4-7 days and 1-3 days, respectively), and only $9 \%$ made this decision after 4-6 weeks.

The majority of psychiatrists (94\%) used various psychological treatments for ADs, as shown by the following answers (the respondent could select several answers): "I explain the symptoms and treatment approaches" (53\% of respondents); "I refer to psychotherapist" (40\%); "I provide short-term psychotherapy (5-10 sessions)" (30\%); "I conduct full-time psychotherapy (over 10 sessions)" (15\%). 


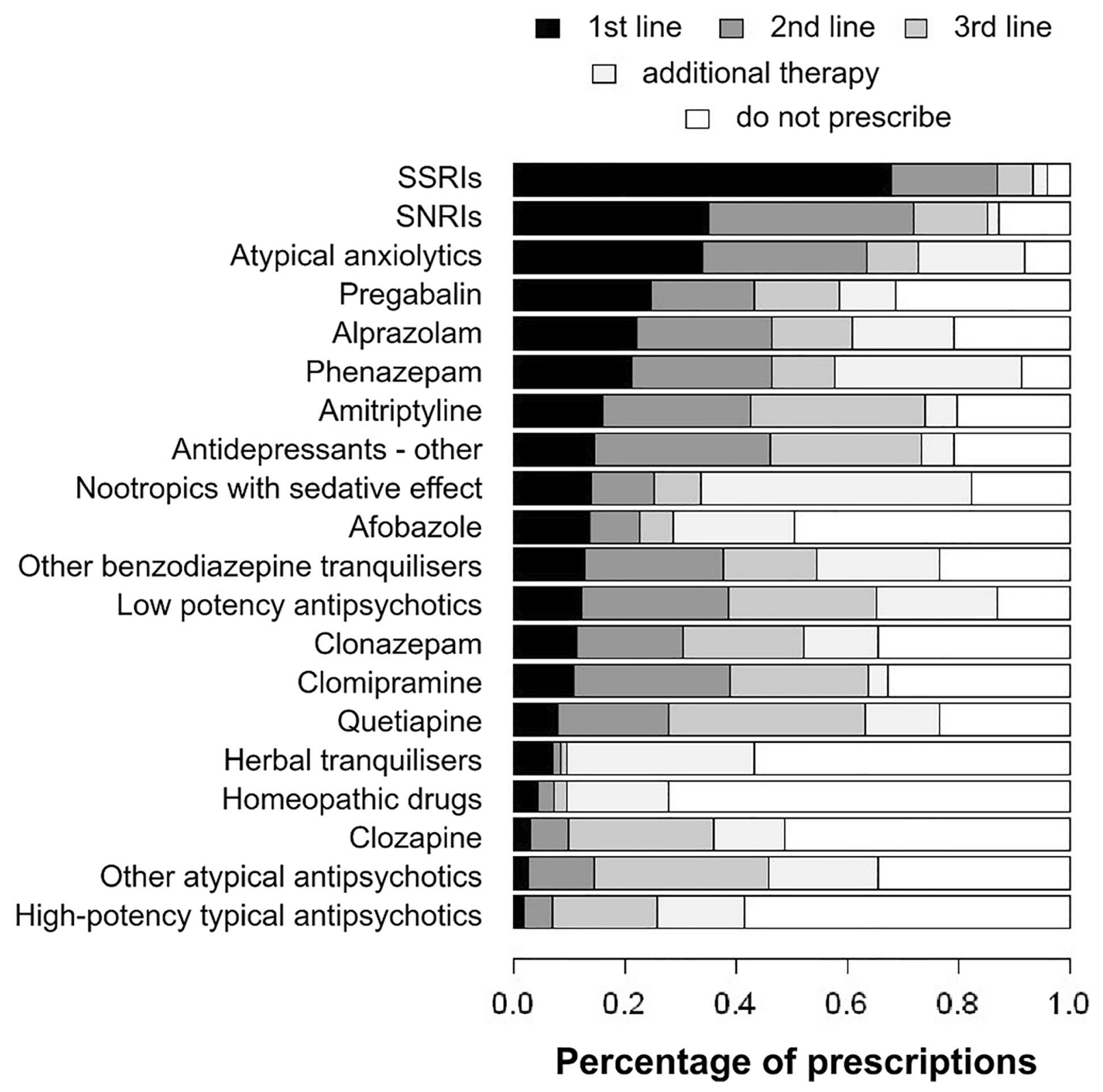

Fig. 5 Proportions of psychiatrists who reported the use of specific medications as the first-, second- and third-line treatment

\section{DISCUSSION}

Overall, 960 psychiatrists from 75 regions of the Russian Federation participated in our survey, which is a more than fourfold increase over the number of Russian psychiatrists $(N=220)$ who participated in the international survey conducted by the WPA and WHO [14].
Our survey showed that Russian clinicians use $\mathrm{AD}$ diagnoses less frequently than shown in the international results, with the only exception being PD. The diagnosis of MADD (F41.2) was the most commonly used diagnosis in both surveys; 67 and 43\% of participating psychiatrists, respectively, used this diagnosis at least once a week. GAD (F41.1) was the second most 
frequently diagnosed disorder in the WPA-WHO survey and the fourth in the RSP survey. The diagnosis of AdD (F43.2) was third in the frequency of use in the WPA/WHO survey and second in the RSP survey (53 and 31\%, respectively). The largest gaps between relative frequency of use of diagnoses in the WPA/WJP international study and our study were found for the categories of Specific phobias and GAD (52 vs. $4 \%$ and 60 vs. $17 \%$, respectively).

Several major underlying factors can contribute to the lower than expected prevalence of ADs in the Russian Federation. First, Russian psychiatrists may not use the diagnoses of ADs due to a strong traditional background of educational approaches [1, 7, 20-23]. For example, less than half of participating psychiatrists used each of the diagnoses of interest on weekly basis and from 38 to $46 \%$ did not use them during the last year, including the diagnoses of specific phobia, social phobia and agoraphobia that have been reported to affect from 2 to $6.4 \%$ of the European population [12]. Moreover, a significantly lower proportion of psychiatrists in our study used these diagnoses at least once a week in comparison to results of the WPA-WHO survey, with the largest differences related to the the diagnosis of GAD, which is a relatively new diagnostic category in Russia compared to other diagnostic categories. Nevertheless, the fact that the majority of respondents (96\%) consider SSRIs to be crucial to the treatment of ADs may reflect a general awareness of current treatment guidelines for ADs, indicating that there may be reasons for the low frequency of making diagnoses of anxiety and stress-related disorders. Another explanation is that the majority of psychiatrists in our study reported that they prefer not to use comorbid diagnoses and suggest this practice is inappropriate. The reason for this non-acceptance of comorbid diagnoses may be due to the strong position of hierarchical principles of dominant diagnosis in Russia [24]. Thus, due to the comorbid nature of $\mathrm{ADs}$ and the low acceptance of making comorbid diagnoses, psychiatrists may use other diagnoses instead.

Another possible major reason for the underdiagnosing of ADs is that patients with anxiety and stress-related disorders may avoid the state psychiatric service or may not be aware of these disorders and/or ignore the morbid nature of ADs. State psychiatric facilities (including outpatient clinics) in Russia are primarily attended by patients with severe mental disorders, which generally worsen the stigma associated with these facilities [25]. Patients with $\mathrm{AD}$ are among those who are in the greatest need of a specialist's attention but, unfortunately, such patients are very sensitive to psychiatric stigmatization [26]. This can underlie our finding that ADs are more frequently diagnosed in non-state psychiatric service while statistical data on prevalence of $\mathrm{ADs}$ is based on state-run institution services.

The pharmacotherapy prescribed for the treatment of ADs by Russian psychiatrists generally complies with international guidelines; however, specialists also often select drugs with unproven efficacy and do not follow the therapeutic algorithms developed on the basis of evidence-based medicine in terms of the sequence of drug choices and the treatment duration.

ADs are associated with a poorer quality of life, decreased functional capacity and a higher risk of somatic disorders [3]. Our study highlights a number of unmet needs in diagnosing anxiety and stress-related disorders that may come from psychiatry organizational problems, psychiatry-associated stigma and lack of knowledge about psychiatric disorders that should be resolved in order to improve the quality of psychiatric service and patient's wellbeing in Russia.

\section{Limitations}

Our study has number of limitations. Only psychiatrists who had internet access were able to participate in the survey and only about 5\% of all Russian psychiatrists took part in this survey. Moreover, the study population may be biased as we suspect that younger psychiatrists who, in comparison to their older colleagues, are more comfortable with IT-technologies, are more socially active and are more likely to follow updates in either the RSP-website or RSP 
pages in social networks, were more inclined to participate in the survey.

Another source of possible bias is that those specialists who regularly engage in the treatment of ADs may have had more inclination to participate in the survey. Thus, real-world data on the diagnosis of ADs probably would be even lower than what was obtained in this survey. Nevertheless, the online nature of the survey allowed us to reach a broad range of specialists countrywide and to create a representative sample of psychiatrists in terms of working settings, professional activity, experience and other parameters that may potentially affect theresults of this study.

Another limitation is that many questions evaluate only roughly the participant's estimation. Therefore, the results should be interpreted with caution and should not be generalized to the entire population of Russian psychiatrists or used instead of, or compared to, the statistical data or the results of epidemiological studies.

\section{CONCLUSIONS}

The results of this survey show that psychiatrists in the Russian Federation use diagnoses of many ADs less frequently than psychiatrists in an international survey. Diagnoses of ADs are most used by specialists inprivate practice and in liaison with psychiatric services in general/somatic medicine. These results may indicate the existence of certain barriers that decrease the availability of psychiatric service for patients with ADs. Among the anxiety and stress-related disorders, the majority of Russian psychiatrists are inclined to diagnose MADD and AdD, which by their nature are more likely to be preliminary diagnoses. The diagnosis of GAD in Russia is used far less than in the rest of the world, while the diagnosis of PD, on the contrary, is used much more often. Diagnoses of ADs tend to be made less often used as the second (comorbid) diagnosis even in the cases when the patient's condition meets the criteria for two or more disorders.

The pharmacotherapy prescribed for the treatment of ADs by Russian psychiatrists generally comply with international guidelines; however, specialists also often select drugs with unproven efficacy and do not follow the therapeutic algorithms developed on the basis of evidence-based medicine in terms of the sequence of drug choices and the treatment duration.

The results of this survey indicate that more efforts should be undertaken to spread information about modern diagnostic and treatment approaches in ADs through medical educational programs, and to overcome various barriers that increase the stigma and decrease the availability of psychiatric service to patients with ADs.

\section{ACKNOWLEDGEMENTS}

The authors would like to thank Prof. Geoffrey Reed for his kind advice and remarks on the study results and Ms. Christine Traxler for her assistance with text adaptation. We are also very grateful to all the clinicians for their wiliness to spent their precious time answering survey questions.

Funding. This research did not receive any specific grant from funding agencies in the public, commercial or not-for-profit sectors. The journal's Rapid Service Fee was paid by Servier Laboratories (Suresnes, France).

Medical Writing/Editorial Assistance. Manuscript formatting support and text adaptation was provided by Ms. Christine Traxler; no contribution was made to editorial content. Timur Syunyakov provided funding for this assistance via https://www.upwork.com.

Authorship. All named authors meet the International Committee of Medical Journal Editors (ICMJE) criteria for authorship for this article, take responsibility for the integrity of the work as a whole, and have given their approval for this version to be published.

Authors' Contributions. NN developed the concept; IM, TS and SM were involved in the study design, formulating the survey questions, 
interpreting the results and carefully revising the manuscript. IM deployed questionnaire on the SoSci Survey platform and posted it on the website. IM, TS and SM prepared the manuscript. TG and IM performed the statistical analyses. All authors approved the final version for publication. All authors provided substantial contributions to the design, acquisition, analysis or interpretation of data for this analysis, and participated in revising the manuscript. The corresponding author (SM) had full access to all the data in the study and had final responsibility for the decision to submit for publication.

Prior Presentation. A part of the preliminary data in this article was presented at the 25th European Congress of Psychiatry, Florence, Italy, April 2017.

Disclosure. The authors declare no conflict of interest and report no financial or other relationship relevant to the subject of this article. Sergey Mosolov has received research grants from, and been involved in clinical trials for Servier, Eli Lilly, Lundbeck, AstraZeneca, Janssen-Cilag, Sanofi-Aventis, Geodon Richter, Stada and Alkermes; and reports speaker fees from Sanofi-Aventis, AstraZeneca, Janssen-Cilag, Pfizer, Geodon Richter, Angellini, Grindex and Servier. Nikolay Neznanov has been involved in clinical trials for Servier, Lundbeck, AstraZeneca, Janssen-Cilag, Sanofi-Aventis, Pfizer, Geodon Richter and Sunovion; and reports speaker fees from Sanofi-Aventis, AstraZeneca, Janssen-Cilag, Pfizer, Geodon Richter, Angellini and Servier. Ivan Martynikhin reports speaker fees from Sanofi-Aventis, Janssen-Cilag, Pfizer, Geodon Richter and Lundbeck. Timur Syunyakov reports speaker fees from Pfizer and Angellini. Timofey Galankin have nothing to declare.

Compliance with Ethics Guidelines. This study was not experimental research and did not involve any patients. All data were received from an anonymous online survey of psychiatrists who voluntarily responded to the questions in the survey. The study did not involve the collection of any personal data. The study and the content of the survey were approved by the Local Ethical Committee of Moscow Research Institute of Psychiatry (19 September 2016; protocol no. 34a), and written participation consent was waived. The study followed the Good Epidemiology Practice guidelines and the principles of the Declaration of Helsinki

.Data Availability. The datasets generated during and/or analyzed during the current study are available from the corresponding author on reasonable request.

Open Access. This article is licensed under a Creative Commons Attribution-NonCommercial 4.0 International License, which permits any non-commercial use, sharing, adaptation, distribution and reproduction in any medium or format, as long as you give appropriate credit to the original author(s) and the source, provide a link to the Creative Commons licence, and indicate if changes were made. The images or other third party material in this article are included in the article's Creative Commons licence, unless indicated otherwise in a credit line to the material. If material is not included in the article's Creative Commons licence and your intended use is not permitted by statutory regulation or exceeds the permitted use, you will need to obtain permission directly from the copyright holder. To view a copy of this licence, visit http://creativecommons.org/licenses/by$\mathrm{nc} / 4.0 /$.

\section{REFERENCES}

1. Leont'ev IL. On reforming the psychiatric care system in the Russian Federation. Probl Sotsialnoi Gig Zdravookhranenniiai Istor meditsiny. 2004;2:36-8 (in Russian).

2. van Voren R. Mental health and human rights in Russia-a flawed relationship. Lancet. 2017;390: 1613-5.

3. Morozov PV. Mental health and urbanization: a Russian perspective. Curr Opin Psychiatry. 2018;31: 272-5.

4. Morozov PV, Maruta NA, Skugarevskiy OA. Training of psychiatrists in Eastern Europe: problems and 
solutions. Int Rev Psychiatry. 2020;32(2):145-50. https://doi.org/10.1080/09540261.2019.1645645

5. Nersessova KS, Jurcik T, Hulsey TL. Differences in beliefs and attitudes toward depression and schizophrenia in Russia and the United States. Int J Soc Psychiatry. 2019;65:388-98.

6. Karpenko O, Kostyuk G. Community-based mental health services in Russia: past, present, and future. Lancet Psychiatry. 2018;5:778-80.

7. Tiganov AS. Controversial problems of clinical psychiatry. Zhurnal Nevrol i psikhiatrii Im SS Korsakova. 2014;114:8-11 (in Russian).

8. Füredi J, Mohr P, Swingler D, et al. Psychiatry in selected countries of Central and Eastern Europe: an overview of the current situation. Acta Psychiatr Scand. 2006; 114:223-31.

9. Ministry of Public Health of Russian Federation. Statistical Bulletin 2018 year. 2019. https://www. rosminzdrav.ru/ministry/61/22/stranitsa-979/statis ticheskie-i-informatsionnye-materialy/statistichesk iy-sbornik-2018-god (in Russian). Accessed 7 Dec 2020.

10. Kekelidze ZI, editor. Psychiatric help to the population of the Russian Federation in 2015-2017 analytical review. Berlin: Federal State Budgetary Institution "Federal Medical and Pharmaceutical Center named after V.P. Serbsky" Ministry of Health of Russia; 2018 (in Russian).

11. Steel Z, Marnane C, Iranpour C, et al. The global prevalence of common mental disorders: a systematic review and meta-analysis 1980-2013. Int J Epidemiol. 2014;43:476-93.

12. Wittchen HU, Jacobi F, Rehm J, et al. The size and burden of mental disorders and other disorders of the brain in Europe 2010. Eur Neuropsychopharmacol. 2011;21:655-79.

13. Neznanov NG, Martynihin IA, Mosolov SN. Diagnosis and treatment of anxiety disorders in the Russian Federation: results of surveys conducted among psychiatrists. Current Ther Mental Disord. 2017;2:2-12. https://doi.org/10.21265/PSYPH. 2017.41.6437 (in Russian).

14. Reed GM, Mendonça Correia J, Esparza P, Saxena S, Maj M. The WPA-WHO global survey of psychiatrists' attitudes towards mental disorders classification. World Psychiatry. 2011;10:118-31.

15. Kazakovtseva BA, Holland VB, editors. Mental disorders and behavioural disorders (Class V of ICD-10 adapted for use in the Russian Federation). Moscow: Ministry of Healthcare of the Russian Federation; 1998 (in Russian).

16. Judd LL, Kessler RC, Paulus MP, Zeller PV, Wittchen HU, Kunovac JL. Comorbidity as a fundamental feature of generalized anxiety disorders: results from the National Comorbidity Study (NCS). Acta Psychiatr Scand Suppl. 1998;393:6-11.

17. Mosolov SN. Anxiety and depressive disorders: comorbidity and therapy. Moscow: Artinfo Publishing; 2007 (in Russian).

18. Bandelow B, Sher L, Bunevicius R, et al. Guidelines for the pharmacological treatment of anxiety disorders, obsessive-compulsive disorder and posttraumatic stress disorder in primary care. Int $\mathrm{J}$ Psychiatry Clin Pract. 2012;16:77-84 https://doi. org/10.3109/13651501.2012.667114.

19. Mosolov SN, Alfimov PV. Algorithm of biological therapy of generalised anxiety disorder. Curr Ther Mental Disord. 2015;2:24-8 (in Russian).

20. Bezchasniy KV. A role of Russian psychiatrists in the formation of forensic psychiatry in Russia in the beginning of XIX century. Zhurnal Nevrol i psikhiatrii Im SS Korsakova. 2016;116:76-81 (in Russian).

21. Iastrebov VS, Mitikhin VG, Solokhina TA, Shevchenko LS, Tvorogova NA. Actual problems of inpatient psychiatric care in Russia. Zhurnal Nevrol i psikhiatrii Im SS Korsakova. 2013;113:4-10 (in Russian).

22. Krasnov VN, Gurovich I. History and current condition of Russian psychiatry. Int Rev Psychiatry. 2012;24:328-33.

23. Iastrebov VS. Modern psychiatric service and criteria for the estimation of its activity. Zhurnal Nevrol i psikhiatrii Im SS Korsakova. 2001;101:29-36 (in Russian).

24. Tiganov AV, Snezhnevsky DD, Orlovskaya DD, et al. , editors. Handbook of psychiatry, volume 1. Moscow: Meditsina; 1999 (in Russian).

25. Gurovich IY. An inreaction of general medicine and psychiatry and the stigma of mental disorders. Russ Med J. 2001;9:1202-3.

26. Alonso J, Buron A, Bruffaerts R, et al. Association of perceived stigma and mood and anxiety disorders: results from the World Mental Health Surveys. Acta Psychiatr Scand. 2008;118:305-14. 